\section{Screening Forms for Patients for MR Procedures and Individuals for the MR Environment}

The establishment of thorough and effective screening procedures for patients and other individuals is one of the most critical components of a program that guards the safety of all those preparing to undergo MR procedures or to enter the MR environment (Shellock and Kanal, 1991, 1994, 1996; Sawyer-Glover and Shellock, 2000, 2001; Shellock, 2001; Kanal et al. 2002). An important aspect of protecting patients and individuals from MR system-related accidents and injuries involves an understanding of the risks associated with the various implants, devices, accessories, and other objects that may cause problems in this setting (Shellock and Kanal, 1991, 1994, 1996; Sawyer-Glover and Shellock, 2000, 2001; Shellock, 2001, 2002a,b, 2003; Kanal et al., 2002; Shellock and Crues, 2002). This requires constant attention and diligence to obtain information and documentation about these objects in order to provide the safest MR setting possible. In addition, because most MR-related incidents have been due to deficiencies in screening methods and/or a lack of properly controlled access to the MR environment (especially with regard to preventing personal items and other potentially problematic objects from getting into the MR system room), it is crucial to set up procedures and guidelines to prevent such incidents from occurring.

\section{MAGNETIC RESONANCE (MR) PROCEDURE SCREENING FOR PATIENTS}

Certain aspects of screening patients for MR procedures may take place during the scheduling process. This should be conducted by a healthcare worker that is specially trained in MR safety (i.e., this person should be trained to understand the potential hazards and issues associated with the MR environment and MR procedures and be familiar with all of the information contained on the screening forms for patients and individuals). During this time, it may be ascertained if the patient has any implant that may be contraindicated for the MR procedure (e.g., a ferromagnetic aneurysm clip, pacemaker, etc.) or if there is any condition that needs careful consideration (e.g., the patient is pregnant, has a disability, etc.). Preliminary screening helps to prevent the scheduling of patients who may be inappropriate candidates for MR examinations (Sawyer-Glover and Shellock, 2000, 2001; Shellock, 2003).

After preliminary screening, every patient must undergo a comprehensive screening in preparation for a magnetic resonance (MR) procedure (i.e., MR imaging, MR angiography, functional MRI, MR spectroscopy). Comprehensive patient screening involves the use of a printed form to document the screening procedure, a review of the information on the screening form, and a verbal interview to verify the information on the form and to allow discussion of any questions or concerns that the patient may have. An MR-safety trained healthcare worker must conduct this aspect of patient screening.

A screening form for patients developed by Sawyer-Glover and Shellock (2000) was recently revised in consideration of new information in the peer-reviewed literature. This two-page form, entitled Magnetic Resonance (MR) Procedure Screening Form for Patients, was also created in conjunction with the Medical, Scientific, and Technology Advisory Board and the Corporate Advisory Board of the Institute for Magnetic Resonance Safety, Education, and Research (IMRSER). A downloadable version of this form may be obtained from the MR safety Web sites, http://www.IMRSER.org and http://www.MRIsafety.com.
Screening Forms

A1.1

Supplement 11 
The first page of this screening form requests general patient-related information (e.g., name, age, sex, height, weight, etc.) as well as information regarding the reason for the MR procedure and/or symptoms that may be present. Pertinent information about the patient is required not only to ensure that the medical records are up-to-date, but also in the event that the MR facility needs to contact the referring physician for additional information regarding the examination or to verify the medical condition of the patient.

The form requests information regarding a prior surgery or operation to help determine if there may be an implant or device present that could create a problem for the patient. Information is also requested pertaining to prior diagnostic imaging studies that may be helpful to review for assessment of the patient's condition.

Next, important questions are posed in an effort to determine if there are possible problems or issues that should be discussed with the patient prior to permitting entry to the MR environment. For example, information is requested regarding any problem with a previous MR examination, an injury to the eye involving a metallic object, or any injury from a metallic object or foreign body. Questions are posed to obtain information about current or recently taken medications as well as the presence of drug allergies. There are also questions to assess past and present medical conditions that may affect the MR procedure or the use of an MRI contrast agent in the patient.

At the bottom of the first page, there is a section for female patients that poses questions that may impact MR procedures. For example, questions regarding the date of the last menstrual period, pregnancy, or late menstrual period are included. A definite or possible pregnancy must be identified prior to permitting the patient into the MR environment so that the risks versus the benefits of the MR procedure can be considered and discussed with the patient. MR procedures should only be performed in pregnant patients to address important clinical questions. MR facilities should have a clearly defined procedure to follow in the event that the patient has a confirmed or possible pregnancy.

Questions pertaining to the date of the last menstrual period and use of oral contraceptives, hormonal therapy, and fertility medication are necessary for female patients undergoing MR procedures that are performed to evaluate breast disease or for OB/GYN (obstetrics gynecology) applications, as these may alter the tissue appearance on MR imaging. An inquiry about breastfeeding is included in case the administration of MRI contrast media is being considered for nursing mothers.

The second page of the form has a statement at the top that states: "WARNING: Certain implants, devices, or objects may be hazardous to you and/or may interfere with the MR procedure (i.e., MRI, MR angiography, functional MRI, MR spectroscopy). Do not enter the MR system room or MR environment if you have any questions or concerns regarding an implant, device, or object. Consult the MRI Technologist or Radiologist BEFORE entering the MR system room. The MR system magnet is ALWAYS on."

Next, there is a section that lists various implants, devices, and objects to identify anything that could be hazardous to the patient undergoing the MR procedure or that may produce an artifact that could interfere with the interpretation of the MR procedure. In general, these items are arranged on the checklist in order of the relative safety hazard (e.g., aneurysm clip, cardiac pacemaker, implantable cardioverter defibrillator, electronic implant, etc.), followed by items that may simply produce imaging artifacts that could be problematic for the interpretation of the MR procedure. Additionally, questions are posed to determine if the patient has a breathing problem, movement disorder, or claustrophobia because these are known to present difficulties for MR procedures.

Figures of the human body are included on the second page of the screening form for the patient as a means of showing the location of any object inside of or on the body. This information is particularly useful so that the patient may indicate the approximate position 
of any object that may be hazardous or that could interfere with the interpretation of the MR procedure by producing an artifact.

The second page of the screening form also has an "Important Instructions" section that states: "Before entering the MR environment or MR system room, you must remove all metallic objects including hearing aids, dentures, partial plates, keys, beeper, cell phone, eyeglasses, hair pins, barrettes, jewelry, body piercing jewelry, watch, safety pins, paperclips, money clip, credit cards, bank cards, magnetic strip cards, coins, pens, pocket knife, nail clipper, tools, clothing with metal fasteners, and clothing with metallic threads. Please consult the MRI Technologist or Radiologist if you have any questions or concerns BEFORE you enter the MR system room."

Finally, there is a statement on the "Magnetic Resonance (MR) Procedure Screening Form for Patients" that indicates hearing protection is "advised or required" to prevent possible problems or hazards related to acoustic noise. In general, this should not be an option for a patient undergoing an MR procedure on a high-field-strength (e.g., $\geq 1.0$-Tesla) MR system. By comparison, it may not be necessary for the use of hearing protection by patients undergoing MR procedures on low-field-strength MR systems.

It should be noted that undergoing previous MR procedures without incidents does not guarantee a safe subsequent MR examination. Various factors (e.g., the static magnetic field strength of the MR system, the orientation of the patient, the orientation of a metallic implant or object, etc.) can substantially change the scenario. Thus, a written screening form must be completed each time a patient prepares to undergo an MR procedure. This is not an inconsequential matter because a surgical intervention or accident involving a metallic foreign body may have occurred that could impact the safety of an MR procedure or of entering the MR environment.

With the use of any type of written questionnaire, limitations exist related to incomplete or incorrect answers provided by the patient. For example, there may be difficulties associated with patients that are impaired with respect to their vision, language fluency, or level of literacy. Therefore, an appropriate accompanying family member or other individual (e.g., referring physician) should be involved in the screening process to verify any information that may impact patient safety. Versions of this form should also be available in other languages, as needed (i.e., specific to the demographics of the MR facility; Sawyer-Glover and Shellock, 2000; Kanal et al. 2002; Shellock, 2003).

In the event that the patient is comatose or unable to communicate, the written screening form should be completed by the most qualified individual (e.g., physician, family member, etc.) that has knowledge about the medical history and present condition of the patient. If the screening information is inadequate, it is advisable to look for surgical scars on the patient and/or to obtain plain films of the skull and/or chest to search for implants that are known to be particularly hazardous in the MR environment (e.g., aneurysm clips, cardiac pacemakers, etc.).

Following completion of the "Magnetic Resonance (MR) Procedure Screening Form for Patients," an MR-safety trained healthcare worker should review the form's content. Next, a verbal interview should be conducted by the MR-safety trained healthcare worker to verify the information on the form and to allow discussion of any questions or concerns that the patient may have before undergoing the MR procedure. This allows for clarification or confirmation of the answers to the questions posed to the patient so that there is no miscommunication regarding important MR safety issues. In addition, because the patient may not be fully aware of the medical terminology used for a particular implant or device, it is imperative that this particular information on the form be discussed during the verbal interview. 
After the comprehensive screening procedure is completed, any patient that is transferred by a stretcher, gurney, or wheelchair to the MR system room should be checked thoroughly and systematically for metal objects under the sheets or blankets such as ferromagnetic oxygen tanks, monitors, or other objects that could pose a hazard.

\section{MAGNETIC RESONANCE (MR) ENVIRONMENT SCREENING FOR INDIVIDUALS}

Before any "non-patient" individual (e.g., MRI technologist, MR support person, family member, visitor, allied health professional, physician, maintenance worker, custodial worker, fire fighter, security officer, etc.) is allowed into the MR environment, he or she must be screened by an MR-safety trained healthcare worker. Proper screening for individuals involves the use of a printed form to document the screening procedure, a review of the information on the form, and a verbal interview to verify the information on the form and to allow discussion of any questions or concerns that the individual may have before permitting entry into the MR environment.

In general, magnetic resonance (MR) screening forms were developed with patients in mind and, therefore, pose many questions that are inappropriate or confusing to other individuals that may need to enter the MR environment. Therefore, a screening form was recently created specifically for individuals that need to enter the MR environment and/or an MR system room. This form, entitled "Magnetic Resonance (MR) Environment Screening Form for Individuals," was developed in conjunction with the Medical, Scientific, and Technology Advisory Board and the Corporate Advisory Board of the Institute for Magnetic Resonance Safety, Education, and Research (IMRSER). A downloadable version of this form may be obtained from the MR safety Web sites, http://www.IMRSER.org and http://www.MRIsafety.com.

At the top of this form, the following statement is displayed: "The MR system has a very strong magnetic field that may be hazardous to individuals entering the MR environment or MR system room if they have certain metallic, electronic, magnetic, or mechanical implants, devices, or objects. Therefore, all individuals are required to fill out this form BEFORE entering the MR environment or MR system room. Be advised, the MR system magnet is ALWAYS on."

The "Magnetic Resonance (MR) Environment Screening Form for Individuals" requests general information (e.g., name, age, address, etc.) and poses important questions to determine if there are possible problems or issues that should be discussed with the individual prior to permitting entry to the MR environment. A warning statement is also provided on the form, as follows: "WARNING: Certain implants, devices, or objects may be hazardous to you in the MR environment or MR system room. Do not enter the MR environment or MR system room if you have any questions or concerns regarding an implant, device, or object." In addition, there is a section that lists various implants, devices, and objects to identify the presence of anything that could be hazardous to an individual in the MR environment (e.g., an aneurysm clip, cardiac pacemaker, implantable cardioverter defibrillator (ICD), electronic or magnetically activated device, metallic foreign body, etc.).

Finally, there is an "Important Instructions" section on the form that states: "Remove all metallic objects before entering the MR environment or MR system room including hearing aids, beeper, cell phone, keys, eyeglasses, hair pins, barrettes, jewelry (including body piercing jewelry), watch, safety pins, paperclips, money clip, credit cards, bank cards, magnetic strip cards, coins, pens, pocket knife, nail clipper, steel-toed boots/shoes, and tools. Loose metallic objects are especially prohibited in the MR system room and 
MR environment. Please consult the MRI Technologist or Radiologist if you have any questions or concerns BEFORE you enter the MR system room."

The proper use of this written form along with thorough verbal screening of the individual by an MR-safety trained healthcare worker should prevent accidents and injuries in the MR environment (Sawyer-Glover and Shellock, 2000; Kanal et al. 2002; Shellock, 2003).

\section{ACKNOWLEDGMENT}

Portions of this text were adapted with permission from Sawyer-Glover and Shellock (2001) The screening forms, "Magnetic Resonance (MR) Procedure Screening Form For Patients" and "Magnetic Resonance (MR) Environment Screening Form for Individuals," were developed in conjunction with the Medical, Scientific, and Technology Advisory Board and the Corporate Advisory Board of the Institute for Magnetic Resonance Safety, Education, and Research (IMRSER) (Shellock, 2003).

\section{LITERATURE CITED}

Kanal, E., Borgstede, J.P., Barkovich, A.J., Bell, C., Bradley, W.G., Felmlee, J.P., Froelich, J.W., Kaminski, E.M., Keeler, E.K., Lester, J.W., Scoumis, E.A., Zaremba, L.A., Zinninger, M.D. 2002. American college of radiology white paper on MR safety. Am. J. Roentgen. 178:1335-1347.

Sawyer-Glover, A. and Shellock, F.G. 2000. Pre-MRI procedure screening: Recommendations and safety considerations for biomedical implants and devices. J. Magn. Reson. Imag. 12:92-106.

Sawyer-Glover, A. and Shellock, F.G. 2001. Pre-magnetic resonance procedure screening. In Magnetic Resonance Procedures: Health Effects and Safety (F.G. Shellock, Ed.). CRC Press, LLC, Boca Raton, Fla.

Shellock, F.G. 2001. New recommendations for screening patients for suspected orbital foreign bodies. Signals, No. 36, Issue 4. pp. 8-9.

Shellock, F.G. 2002a. Biomedical implants and devices: Assessment of magnetic field interactions with a 3.0-Tesla MR system. J. Magn. Reson. Imaging 16:721-732.

Shellock, F.G. 2002b. MR safety update 2002: Implants and devices. J. Mag. Res. Imaging 16:485-496.

Shellock, F.G. 2003. Reference Manual for Magnetic Resonance Safety. Edition. Amirsys, Salt Lake City, Utah.

Shellock, F.G. and Crues, J.V. 2002. Commentary. MR safety and the American College of Radiology White Paper. Am. J. Roentgen. 178:1349-1352.

Shellock, F.G. and Kanal, E. 1991. Policies, guidelines, and recommendations for MR imaging safety and patient management. J. Magn. Reson. Imaging 1:97-101.

Shellock, F.G. and Kanal, E. 1994. SMRI Report. Policies, guidelines and recommendations for MR imaging safety and patient management. Questionnaire for screening patients before MR procedures. J. Magn. Reson. Imaging 4:749-751.

Shellock, F.G. and Kanal, E. 1996. Magnetic Resonance: Bioeffects, Safety, and Patient Management. Second Edition, Lippincott-Raven Press, New York.

\section{INTERNET RESOURCES}

http://www.MRIsafety.com

http://www.IMRSER.org

Contributed by Frank G. Shellock

Keck School of Medicine

University of Southern California and

Institute for Magnetic Resonance Safety, Education, and Research

Los Angeles, California 

MAGNETIC RESONANCE (MR) PROCEDURE SCREENING FORM FOR PATIENTS

Date 1

Name Last name

First name

Middle Initial

Date of Birth

month day year

Address

month day year

City

State

Reason for MRI and/or Symptoms

Referring Physician

Zip Code
Patient Number

Age __ Height ____ Weight

Male $\square$ Female $\square \quad$ Body Part to be Examined

Telephone (home)

Telephone (work)

1. Have you had prior surgery or an operation (e.g., arthroscopy, endoscopy, etc.) of any kind? If yes, please indicate the date and type of surgery:

Date ___ Type of surgery

Date Type of surgery

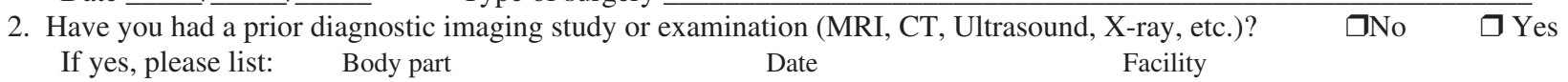

MRI

CT/CAT Scan

X-Ray

Ultrasound

Nuclear Medicine

Other
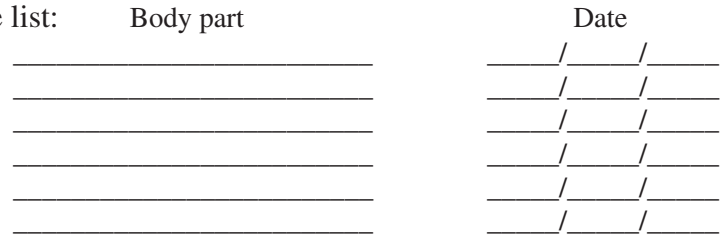
Facility

3. Have you experienced any problem related to a previous MRI examination or MR procedure? If yes, please describe:

4. Have you had an injury to the eye involving a metallic object or fragment (e.g., metallic slivers, shavings, foreign body, etc.)?

If yes, please describe:

5. Have you ever been injured by a metallic object or foreign body (e.g., BB, bullet, shrapnel, etc.)? If yes, please describe:

6. Are you currently taking or have you recently taken any medication or drug? If yes, please list:

7. Are you allergic to any medication? If yes, please list:

8. Do you have a history of asthma, allergic reaction, respiratory disease, or reaction to a contrast medium or dye used for an MRI, CT, or X-ray examination?

9. Do you have anemia or any disease(s) that affects your blood, a history of renal (kidney) disease, or seizures?

If yes, please describe:

$\square$ No $\square$ Yes 


WARNING: Certain implants, devices, or objects may be hazardous to you and/or may interfere with the
MR procedure (i.e., MRI, MR angiography, functional MRI, MR spectroscopy). Do not enter the MR system room
or MR environment if you have any question or concern regarding an implant, device, or object. Consult the MRI
Technologist or Radiologist BEFORE entering the MR system room. The MR system magnet is ALWAYS on.

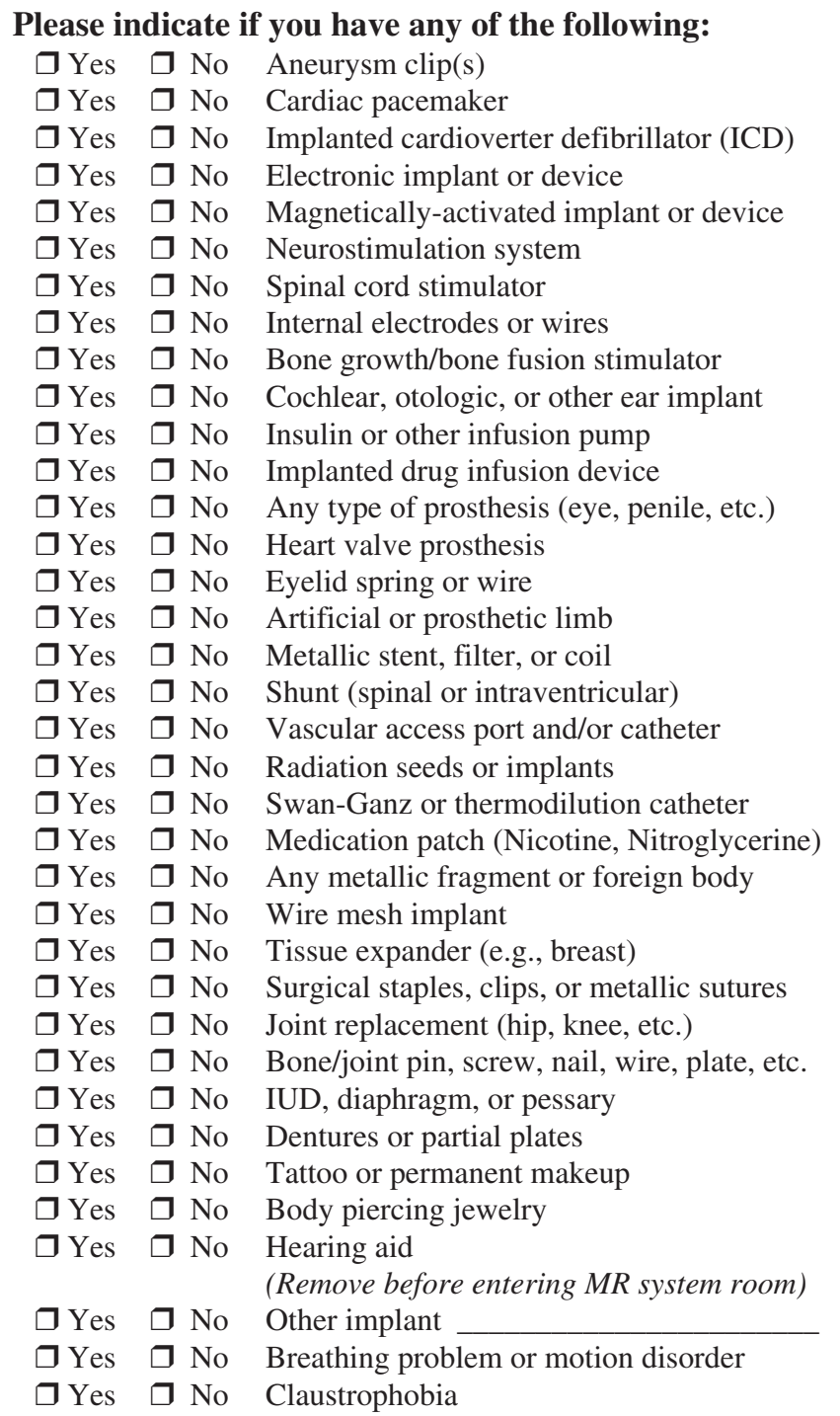

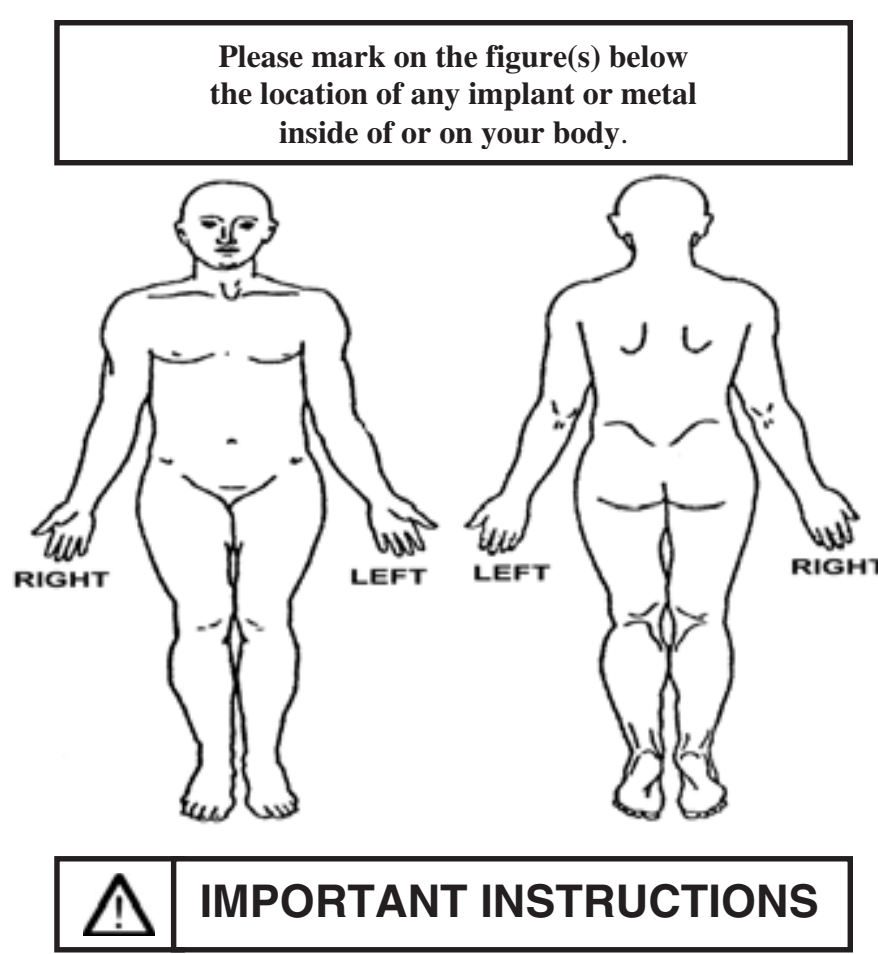

Before entering the MR environment or MR system room, you must remove all metallic objects including hearing aids, dentures, partial plates, keys, beeper, cell phone, eyeglasses, hair pins, barrettes, jewelry, body piercing jewelry, watch, safety pins, paperclips, money clip, credit cards, bank cards, magnetic strip cards, coins, pens, pocket knife, nail clipper, tools, clothing with metal fasteners, \& clothing with metallic threads.

Please consult the MRI Technologist or Radiologist if you have any question or concern BEFORE you enter the MR system room.

NOTE: You may be advised or required to wear earplugs or other hearing protection during the MR procedure to prevent possible problems or hazards related to acoustic noise.

I attest that the above information is correct to the best of my knowledge. I read and understand the contents of this form and had the opportunity to ask questions regarding the information on this form and regarding the MR procedure that I am about to undergo.

Signature of Person Completing Form:

Signature

Date 1

Form Completed By: $\square$ Patient $\square$ Relative $\square$ Nurse

Print name

Relationship to patient

Form Information Reviewed By:
MRI Technologist
Nurse
Radiologist

Signature 


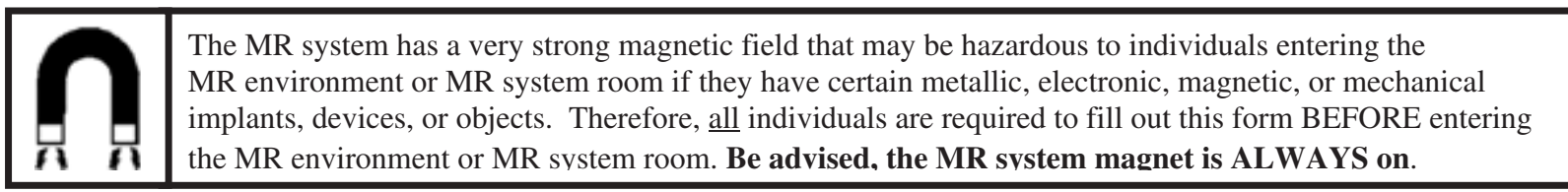

*NOTE: If you are a patient preparing to undergo an MR examination, you are required to fill out a different form.

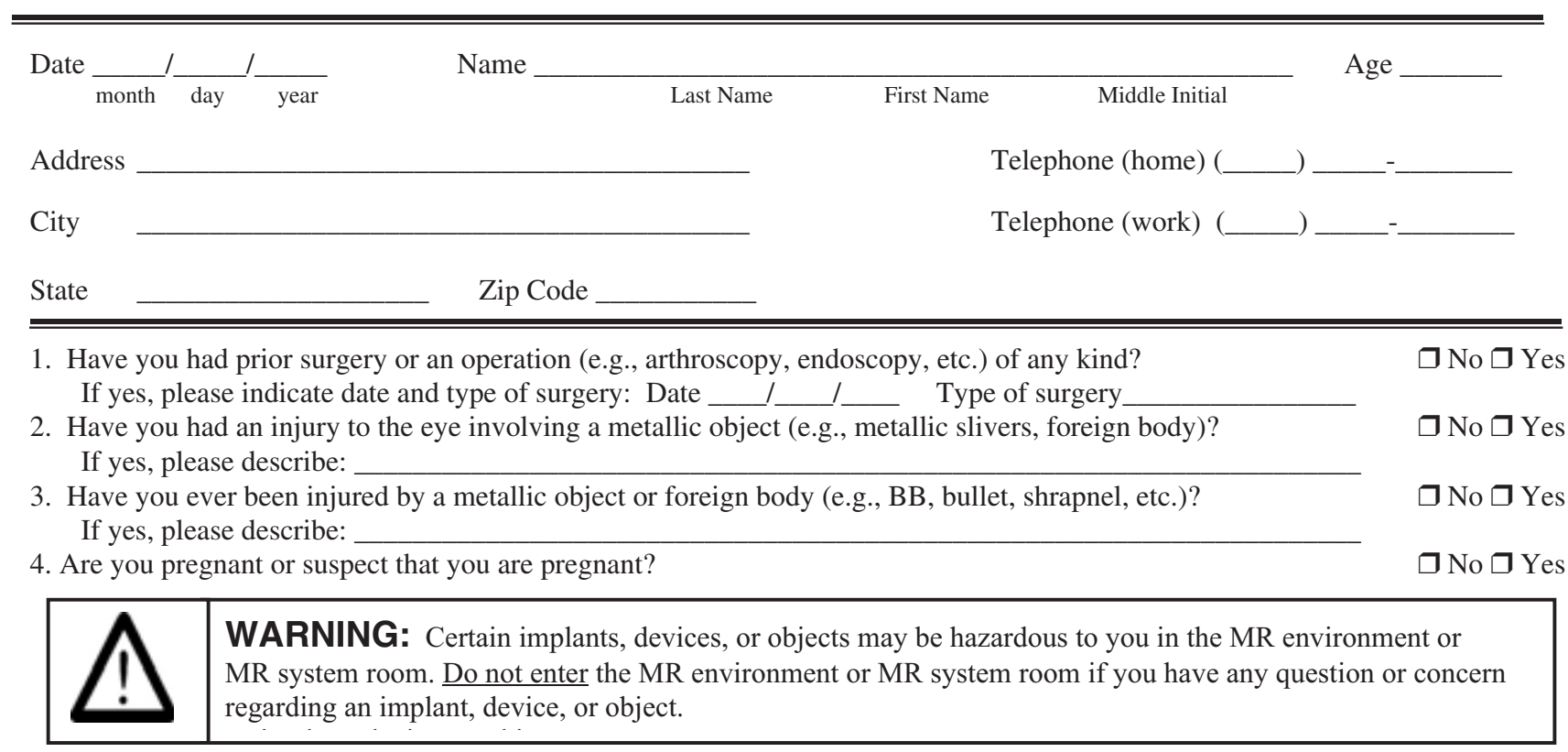

Please indicate if you have any of the following:

$\square$ Yes $\square$ No Aneurysm clip(s)

$\square$ Yes $\square$ No Cardiac pacemaker

$\square$ Yes $\square$ No Implanted cardioverter defibrillator (ICD)

$\square$ Yes $\square$ No Electronic implant or device

$\square$ Yes $\square$ No Magnetically-activated implant or device

$\square$ Yes $\square$ No Neurostimulation system

$\square$ Yes $\square$ No Spinal cord stimulator

$\square$ Yes $\square$ No Cochlear implant or implanted hearing aid

$\square$ Yes $\square$ No Insulin or infusion pump

$\square$ Yes $\square$ No Implanted drug infusion device

$\square$ Yes $\square$ No Any type of prosthesis or implant

$\square$ Yes $\square$ No Artificial or prosthetic limb

$\square$ Yes $\square$ No Any metallic fragment or foreign body

$\square$ Yes $\square$ No Any external or internal metallic object

$\square$ Yes $\square$ No Hearing aid

(Remove before entering the MR system room)

$\square$ Yes $\square$ No Other implant

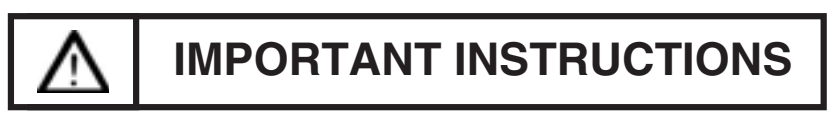

Remove all metallic objects before entering the MR environment or MR system room including hearing aids, beeper, cell phone, keys, eyeglasses, hair pins, barrettes, jewelry (including body piercing jewelry), watch, safety pins, paperclips, money clip, credit cards, bank cards, magnetic strip cards, coins, pens, pocket knife, nail clipper, steel-toed boots/shoes, and tools. Loose metallic objects are especially prohibited in the MR system room and MR environment.

Please consult the MRI Technologist or Radiologist if you have any question or concern BEFORE you enter the MR system room.

I attest that the above information is correct to the best of my knowledge. I have read and understand the entire contents of this form and have had the opportunity to ask questions regarding the information on this form.

Signature of Person Completing Form: Signature

Date 1

Form Information Reviewed By:

Print name

Radiologist
Signature

Other 